Original Research Article

\title{
A 6 months retrospective observational study to assess the rationality and effectiveness of snake bite management in a tertiary care teaching hospital of rural Bengal, India
}

\author{
Satrajit Dan, Ananya Mandal*, Abhijit Das, Sourav Chakrabarty, Tanmoy Gangopadhyay
}

Department of Pharmacology, Bankura Sammilani Medical College, Bankura, West Bengal, India

Received: 11 July 2018

Revised: 28 July 2018

Accepted: 11 August 2018

*Correspondence to:

Dr. Ananya Mandal,

Email: drananyamandal@ gmail.com

Copyright: (C) the author(s), publisher and licensee Medip Academy. This is an openaccess article distributed under the terms of the Creative Commons Attribution NonCommercial License, which permits unrestricted noncommercial use, distribution, and reproduction in any medium, provided the original work is properly cited.

\begin{abstract}
Background: Snake envenomation is a common life-threatening problem encountered all-over West Bengal particularly in the rural areas. There are a large number of patients attending the Emergency unit and being admitted to the Medicine ward, some in the intensive care unit (ICU) and intensive therapy unit (ITU) of the tertiary health care facilities. The objective of this study was to assess rationality and effectiveness of management of venomous snake bite following standard protocol - Standard treatment guidelines of Government of West Bengal and National snakebite management protocol of Government of India.

Methods: This was a retrospective observational study of six months (May October 2017) duration. Data were collected from the treatment records of patients admitted with history of snake bite in the Medicine ward, ICU and ITU of tertiary care teaching hospital of rural Bengal.

Results: Of the 63 venomous bite patients, most (82.5\%) were diagnosed to have features of neurotoxic envenomation. All of them (100\%) received anti-snake venom (ASV). There was no incidence of anaphylactic reaction as well as any serious adverse drug reaction following ASV administration. Two patients developed acute renal failure, needed haemodialysis. Overall percentage of mortality was $3.2 \%$.

Conclusions: The survival rate in venomous snake bite is found to be high in this institution. The practice of snake bite management is found to be adherent with standard protocol. A multicentric study of longer duration is suggested to draw a firm conclusion.
\end{abstract}

Keywords: Antisnakevenom serum (AVS), Snake envenomation, Snake bite management protocol, Snake bite

\section{INTRODUCTION}

Venomous snakes are seen in all over the world, so snake bites are also prevalent worldwide. Globally the nonvenomous species predominate over the venomous ones. India has the highest mortality from snakebite in the world. ${ }^{1}$ Roughly 200000 people are bitten by venomous snakes in India annually. The case fatality rate is around 35000 to 50000 every year from venomous snake-bite in India, which is nearly half of the global figure (approximately 125000 annually)., ${ }^{2,3}$
It is one of the commonest public health related problem in all over the country including West Bengal. The incidence of snake bite is much higher in the rural areas, as most of them are farmers or field-workers by profession. Most of the case fatalities are due to delay in the initiation of definitive management, negligence of patient or relatives, superstitions and lack of education and poor transport system. Sometimes there is hesitation to start the definitive treatment i.e. anti-snake venom (ASV) on the part of health care providers. Further according to studies only $7.23 \%$ of the snakebites reach the hospital set up. ${ }^{4}$ Among the states, Uttar Pradesh, Andhra Pradesh, Bihar, 
Tamil Nadu, West Bengal, Maharashtra and Kerala lead in terms of snake envenomation cases. ${ }^{4}$

In India, there are about 216 species of snakes, out of which around 60 are venomous. ${ }^{1}$ The venomous snakes found in India belong to the families of Elapidae and Viperidae. Common Indian Elapids are common cobra (Najanaja) and common krait (Bungrauscoeruleus) whereas common Indian Viperids are Russel's Viper (Viper russelle) and Saw Scaled Viper (Echiscarinatus).

The definitive antidote i.e polyvalent anti-snake venom (ASV) is very active against envenomation by all these four common venomous species when administered within a stipulated period and it is now freely available in all tiers of Government health care facilities.

The dose of ASV is not fixed and it varies accordingly depending upon the extent of envenomation. In case of a neuroparalytic snake bite 10 vials of ASV need to be given stat via IV infusion followed by a second dose of 10 vials after one hour if there is no improvement within the first hour. In a case of vasculotoxic snakebite there are two prescribed regimens - low dose infusion therapy and high dose intermittent bolus therapy, either of which can be used. The low dose infusion therapy is 10 vials for Russel's viper or 6 vials for Saw scaled viper over 30 minutes then 2 vials six hourly as an infusion in $100 \mathrm{ml}$ of normal saline till the clotting time is normal or for three days whichever is earlier. High dose intermittent bolus therapy entails 10 vials of polyvalent ASV stat over 30 minutes as infusion, followed by 6 vials 6 hourly as bolus therapy till clotting time normalizes and/or local swelling subsides. The total requirement of ASV vials is between 10 to 30 vials depending on the patient condition. ${ }^{4}$

A country wide study was conducted in 2007 and it was seen that timely administration of ASV can save up to 66 percent lives. In January 2016, the Department of Health and Family Welfare, Government of India released a standard treatment protocol for the treatment of snake bites in India. ${ }^{4}$

The aim of this study was to assess rationality and effectiveness of venomous snake bite management in a tertiary care teaching hospital in rural West Bengal following standard protocol.

\section{METHODS}

It is a retrospective observational study carried out in the Department of Pharmacology, in a tertiary care teaching hospital in Bankura district of rural Bengal in association with the Departments of Medicine and Pediatrics. Since Bankura Sammilani Medical College is a tertiary care hospital catering to two large districts, the patient population belong to districts of Purulia, Bankura and part of Medinipur. Most of the patients encountered were referred from primary health care set ups.

\section{Study duration}

The duration of this study was six months between $1^{\text {st }}$ May and $31^{\text {st }}$ October 2017. Data were collected from the treatment records of the patients with history of snake bites admitted in the Medicine ward, ICU and ITU of the hospital for the stipulated time period of five months i.e. $1^{\text {st }}$ June to $31^{\text {st }}$ October 2017 . Authors have chosen the time period including rainy season because the incidence of snake bite is higher during this time. Previous reports from the hospital records have shown a raised incidence of snake bites during this time of the year followed by a fall during the winter months when the snakes hibernate.

\section{Data collection and analysis}

All the treatment record sheets were collected from central record section of the hospital. A case record form was used for each patient to record the treatment administered to the patient as well as the symptoms and outcome of the patient. The information from the case record forms was transcribed to a Microsoft Excel sheet from where they were analyzed further. Tools of descriptive statistics were used to analyze the data and statistical software SPSS (Version 22) was used for this purpose.

To analyze if the treatment given to the patients was rational and according to the standard treatment guidelines, we compared individual treatment with the Standard Treatment Guidelines for Primary healthcare facilities by Institute of Family Health and Welfare, Government of West Bengal and National Snakebite Management Protocol by Government of India. ${ }^{4,5}$ These guidelines were taken as standard and rational and each of the cases were compared accordingly.

\section{RESULTS}

\section{Demography, clinical signs/symptoms and drug usage pattern}

Authors came across a total number of 77 snakebite cases during the stipulated time period, of which 63 venomous and rest 14 non-venomous bite cases. Though incidence of non-venomous bite is much higher globally, in this institute the number is low as it is tertiary care hospital and most of the non-venomous bite patients were managed locally. The non-venomous bite patients were treated symptomatically and were uneventful. We took the venomous bite cases in account, of which $82 \%(n=52)$ were diagnosed to be neurotoxic envenomation and rest $18 \%(\mathrm{n}=11)$ were hematotoxic.

According to age, most of the victims i.e. $83.3 \%(n=52)$ belonged to the age group between 18- 60 years, $9.5 \%$ $(n=6)$ were over 60 years and $7.2 \%(n=5)$ below 18 years. Of these $69 \%(n=43)$ were males and rest $31 \%(n=20)$ were females. According to profession, 57\% $(n=36)$ of the victims were field workers or farmers, followed by $31 \%$ $(n=20)$ household workers, $5 \%(n=3)$ vendors, $5 \%$ students 
and $2 \%(n=1)$ teacher. (Figure 1, Figure 2 and Figure 3). Out of total 63 venomous bite patients, $46(73 \%)$ were referred from primary health care facilities and $17(27 \%)$ presented directly.

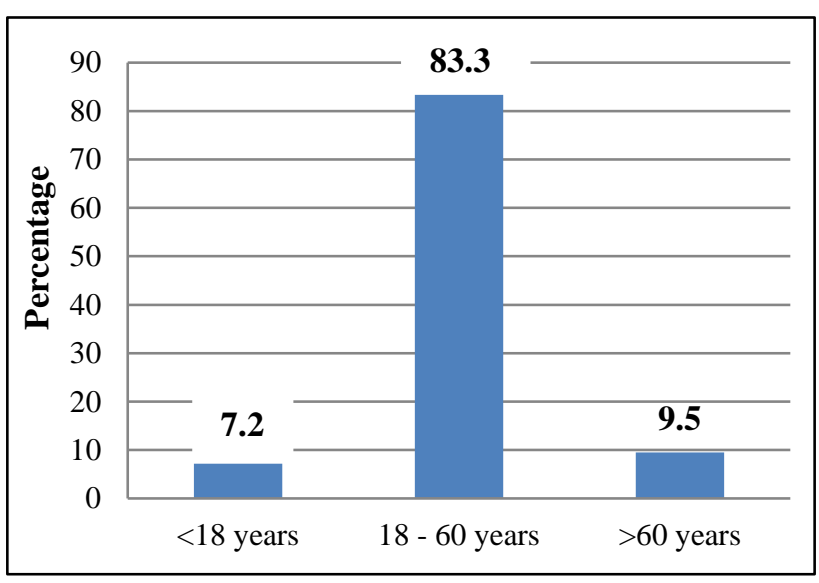

Figure 1: Age distribution.

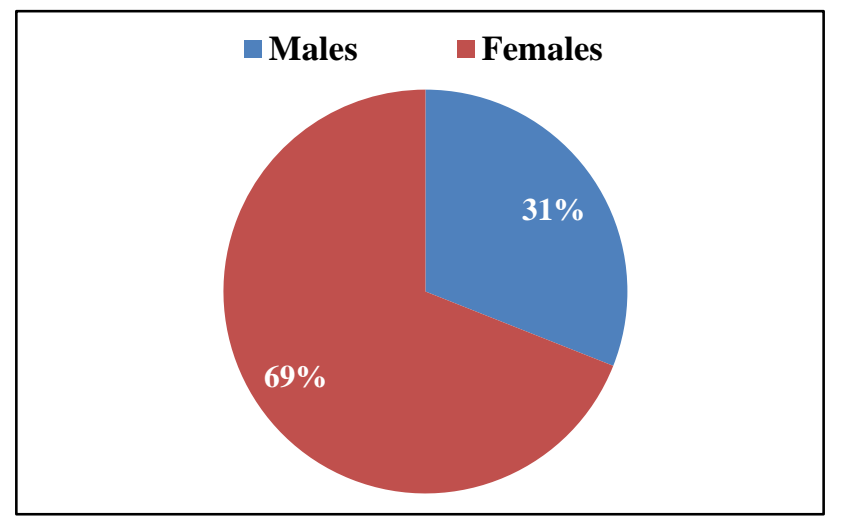

Figure 2: Gender distribution.

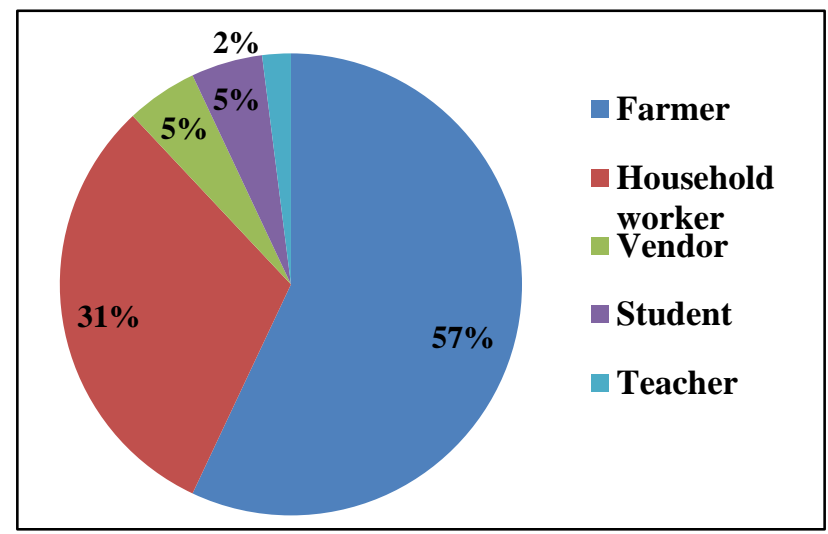

Figure 3: Distribution of the patients according to occupation.

Clinically, bite mark was present in $54 \%(n=34)$ persons. Other local signs and symptoms include edema of the site $(38 \%, n=24)$, pain $(33 \%, n=21)$, bleeding from the wound $(7.9 \%, \mathrm{n}=5)$. Commonest systemic manifestation was vomiting which was present in $20(31 \%)$ patients.
Abdominal pain was present in $9.5 \% \quad(n=6)$ patients. Neurological signs and symptoms were ptosis, dysphagia, numbness and shortness of breath. Hematuria, which is supposed to be the most consistent feature of hematotoxic bite, was present in 2 patients $(3.1 \%)$. Frothing was present in 2 patients (3.1\%) (Figure 4$)$

In drug usage pattern, we saw that all the patients with venomous bites received ASV along with normal saline (NS). All the patients received ASV with anti-histamine (inj. Promethazine in 26 patients i.e. 41.3\%) or corticosteroid (inj. dexamethasone in 42 patients i.e. $66.7 \%$ or inj. hydrocortisone in 14 patients i.e. $22.2 \%$ ) or both. Inj. Tetanus Toxoid was given to the patients only who were not referred from primary health care facilities, the number is $17(27 \%)$.

All the patients with venomous bites, both referred or nonreferred ones, received at least $100 \mathrm{ml}$ ASV. Antibiotics were prescribed to 45 patients $(71.4 \%)$ which include ceftriaxone, ampicillin, metronidazole, amoxicillin and clavulanic acid etc. All preparations were injectable. Inj. Neostigmine and atropine were used in $19 \%(\mathrm{n}=12)$ patients. All patients received gastric acid suppressants in injectable form to prevent stress ulcers. Out of 63 venomous bite patients, inj. Ranitidine was given to 49 (77.7\%) patients and inj. Pantoprazole to rest 14 (22.3\%). Inj. Dicyclomine and inj. Drotaverine were given to $6.3 \%$ $(n=4)$ and $4.7 \% \quad(n=3)$ patients respectively as antispasmodic to treat abdominal pain. A significant number of patients $49.2 \%(n=31)$ received inj. Ondansetron to treat nausea and vomiting. Other drugs used were inj. Furosemide, inj. Glycopyrolate, inj. Theophylline plus etophylline and tab. Alprazolam (Figure 5).

\section{Other significant findings including outcome}

All the venomous bite patients referred from primary health care facilities (73\% of total venomous bite patients) received ASV along with NS, inj. Dexamethasone and inj. Tetanus toxoid from there. We noted that $33 \%$ of the victims had delayed administration of ASV i.e. at least 4 hours after bite. Many reasons could be attributed to this. The most important one was the distance travelled by the patient and their family to the health care set up. Most patients are misinformed about the availability of the ASV and primary medications at the PHI and journey to the tertiary care centre. One of the findings from out studies was the relatively low incidence of use of traditional methods of treatment of envenomation and resultant delays.

There was no incidence of anaphylactic reactions or any serious adverse reactions following ASV administration. Of the hematotoxic bite patients - 2 patient (18.2\%) developed acute renal failure (ARF) and needed hemodialysis, 1 patient developed cellulitis, but there was no death. Two (2) persons with neurotoxic bites died, which was $3.2 \%$ of total venomous bite patients. 


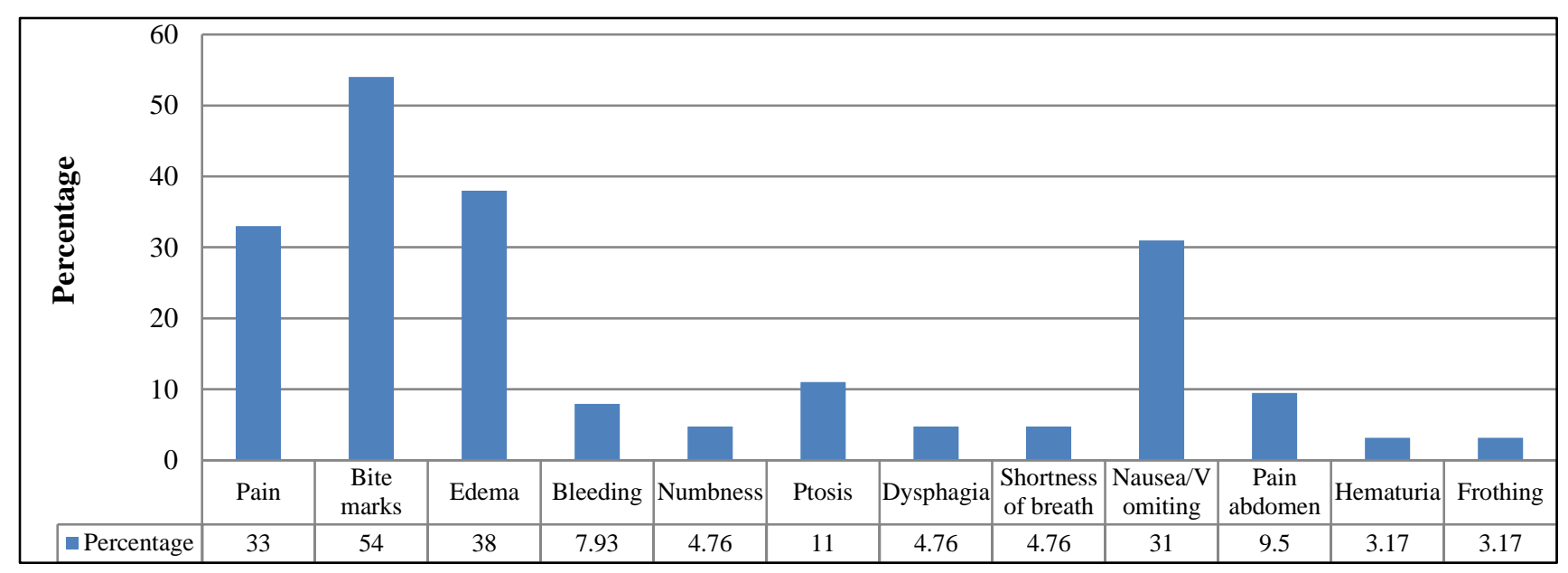

Figure 4: Clinical presentation of the cases.

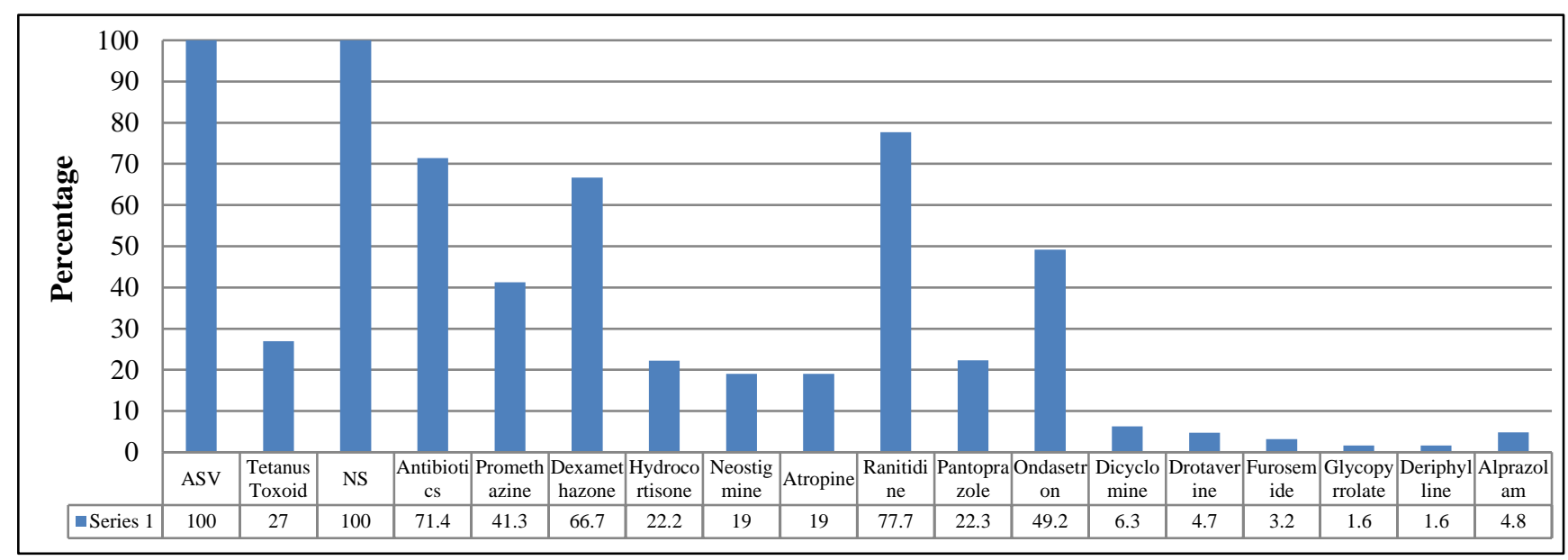

Figure 5: Drug usage pattern among the cases.

\section{DISCUSSION}

During the time of rainy season, the incidence of snake bite and resulting mortality is high. There are very few studies that aimed towards the rationality and effectiveness of its management. The present study was planned to find out the rationality and effectiveness of snake bite management in a tertiary care teaching hospital.

Though incidence of non-venomous bite is higher globally, in this institute the number is low as it is tertiary care hospital and most of the non-venomous bite patients were managed locally. Most of the patients were referred from PHI. All suspected venomous bite patients received ASV in this institute. The patients referred from PHI were also given ASV. There was no incidence of anaphylactic reactions or any other serious adverse reactions after administration of ASV, may be due to prior administration of antihistamine or corticosteroid or both. $33 \%$ of total venomous bite patients had delayed administration of ASV, though the delay was not due to hesitations in the part of health care givers. It was mostly due to delay during transport from remote areas. $57.1 \%$ patients with delayed administration of ASV developed different signssymptoms and complications.

One of the encouraging findings from this study was the relative lack of traditional remedies, herbal medicine, witch doctors etc. Yet field training on first aid in snake bite management is vital in saving lives. Peripheral staff need to be taught the vital use of ASV at first contact and prohibition of cutting, suction of wound, putting arterial tourniquets, alcohol use, cauterization etc.

Previous studies have shown mortality rates of 5 to 10 percent. ${ }^{6-9}$ The outcome we have seen that 2 patients died out of 63 venomous bite patients, both of them had neurotoxic bites and delayed administration of ASV. No patient developed any residual organ damage or residual neurodeficit. Average hospital stay was 3.8 days, which may be lowered if the complications could be avoided by more prompt administration of ASV and by rapid transfer of victim to the health care facilities. 
Our study was a retrospective study, so patients could not be interviewed. It is a single centre study of short duration. Further long term studies could provide a better picture of ASV usage and management of snake bite patients.

Some of the major challenges identified in rational management of snake bite cases include remoteness of the locations where the cases take place. Most snake bite prone areas are in remote locations and the cost of snake bite management is also prohibitive. Access to government facilities that provide not only ASV but also supportive care such as dialysis and ventilation is the major cause of mortality in snake bite management.

Another major hurdle perceived was the lack of uniformity in adherence to standard protocols of snake bite management. There have been several international as well as national standardized protocols for snake bite management. Most healthcare workers are not aware of the latest changes and follow varied treatment protocols. For example there was a confusion among healthcare workers regarding low dose infusion and high dose ASV management. Health care workers at the PHIs are even more ignorant about the different protocols that are approved and recommended for use. The recommendations from the manufacturers are often misleading. ${ }^{10}$ In some nations such as Nepal where snake bites are fairly common, there is a wide range of mortality and case fatality from snake bites between 3 and 58 percent and this is attributed to this varied protocol adherence. ${ }^{11} \mathrm{~A}$ significant problem faced in this set up as well as in many other regions is lack of adequate field-appropriate diagnostic tools to identify species of the snake and the type of envenomation. Poor identification of the type of snake bite leads to poor case definitions, uncertain management, miscalculation in snake bite epidemiology etc. ${ }^{12}$ In most of South Asia including India, old generation snake antivenoms are still in use and there are many venomous species of snakes that are not covered by the existing ASV.${ }^{13}$ Further there is little work on comparative bioequivalence studies of the Indian manufactured ASV preparations. WHO recently has emphasized on strengthening ASV production standardization and this could have an impact on the costs of the ASV products in the market. ${ }^{14,15}$

What was lacking among healthcare workers, primary responders and general public was knowledge regarding snake bite. Care givers and rural communities need to be made aware of the types of snake bites, first aid, importance of rapid transport, dos and don't's etc. There have been studies showing that many doctors in India and Pakistan are not clear about the criteria for ASV administration. This gap in education needs to be bridged. ${ }^{16,17}$

\section{CONCLUSION}

To conclude, prompt administration of ASV along with other supportive measures reduces mortality rate as has been seen in several studies. ASV should be administered as soon as possible in doubtful situations to prevent deaths. This study has highlighted some of the hurdles that can be managed to prevent deaths due to snake bites.

\section{ACKNOWLEDGEMENTS}

Authors would like to the staff and faculty of Departments of Medicine, Pediatrics and Anaesthesiology for their cooperation and help without which this study would not have been possible.

Funding: No funding sources Conflict of interest: None declared

Ethical approval: The study was approved by the Institutional Ethics Committee

\section{REFERENCES}

1. Mohapatra B, Warrell DA, Suraweera W, Bhatia P, Dhingra N, Jotkar RM, et al. Snakebite Mortality in India: A Nationally Representative Mortality Survey PLoS Negl Trop Dis. 2011;5:e1018.

2. Brunda G, Sashidhar RB. Epidemiological profile of snake-bite cases from Andhra Pradesh using immunoanalytical approach. Indian J Med Res. 2007;125:661-8.

3. Chippaux JP. Snake-bites: appraisal of the global situation. Bull World Health Organ. 1998; 76: 515-24.

4. Standard Treatment Guidelines. Management of Snakebite; January 2016. Ministry of Health and Family Welfare. Available at: http://www.nhm.gov.in/nrhm-instate/520-standardtreatment-guidelines.html Accessed 27th July 2018.

5. Standard Treatment Guidelines for Primary Healthcare facilities. Institute of Health and Family Welfare, Kolkata West Bengal. Available at: http://www.ihfwkolkata.org/stg/stg2.html\# Accessed 27th July 2018.

6. Kulkarni ML, Anees S. Snake venom poisoning: Experience with 633 cases. Indian Pediatr. 1994;31:1239-43.

7. Bawaskar HS, Bawaskar PH. Profile of snakebite envenoming in western Maharashtra, India. Trans $\mathrm{R}$ Soc Trop Med Hyg. 2002;96:79-84.

8. Punde DP. Management of snake-bite in rural Maharashtra: A 10-year experience. Natl Med J India. 2005;18:71-5.

9. Bawaskar HS, Bawaskar PH, Punde DP, Inamdar MK, Dongare RB, Bhoite RR, et al. Profile of snakebite envenoming in rural Maharashtra, India. J Assoc Physicians India. 2008;56:88-95.

10. Simpson ID, Norris RL. Snake antivenom product guidelines in India: the devil is in the details. Wilderness Environ Med. 2007;18:163-8.

11. Sharma SK, Khanal B, Pokhrel P, Khan A, Koirala S. Snake bite reappraisal of the situation in eastern Nepal. Toxicon. 2003;41:285-9. 
12. Isbister GK. Snake antivenom research: the importance of case definition. Emerg Med J. 2007;22:399-400.

13. Simpson ID, Norris RL. Snakes of medical importance in India: is the concept of the Big 4 still relevant and useful? Wilderness Environ Med. 2007;18:2-9.

14. Rabies and envenomings: a neglected public health issue: report of a consultative meeting, World Health Organization, Geneva; 10 January 2007. Available at: http://apps.who.int/iris/bitstream/handle/10665/43858 /9789241563482_eng.pdf?sequence $=1$ andisAllowed $=$ y. Accessed 27th July 2018.

15. Simpson ID, Norris RL. The global snakebite crisis-a public health issue misunderstood, not neglected. Wilderness Environ Med. 2009;20:43-56.

16. Simpson ID. A study of the current knowledge base in treating snake bite amongst doctors in the high-risk countries of India and Pakistan: does snake bite treatment training reflect local requirements? Trans $\mathrm{R}$ Soc Trop Med Hyg. 2008;102:1108-14.

17. Sharma SK, Chappuis F, Jha N, Bovier PA, Loutan L, Koirala S. Impact of snake bites and determinants of fatal outcomes in southeastern Nepal. Am J Trop Med Hyg. 2004;71:234-8.

Cite this article as: Dan S, Mandal A, Das A, Chakrabarty S, Gangopadhyay T. A 6 months retrospective observational study to assess the rationality and effectiveness of snake bite management in a tertiary care teaching hospital of rural Bengal, India. Int J Basic Clin Pharmacol 2018;7:2047-52. 